\title{
Dynamic Behavior of Fault Slip Induced by Stress Waves
}

\author{
Guang-an Zhu, ${ }^{1,2}$ Lin-ming Dou, ${ }^{2}$ Yang Liu, ${ }^{1,2}$ Zhen-guo Su, ${ }^{1,2}$ Hui Li, ${ }^{1,2}$ \\ Yong Kong, ${ }^{1,2}$ and $\mathrm{Zhen}-\mathrm{lei} \mathrm{Li}^{1,2}$ \\ ${ }^{1}$ School of Mines, China University of Mining and Technology, Xuzhou 221116, China \\ ${ }^{2}$ State Key Laboratory of Coal Resources and Safe Mining, School of Mines, China University of Mining and Technology, \\ Xuzhou 221116, China
}

Correspondence should be addressed to Lin-ming Dou; lmdou@126.com

Received 23 May 2015; Accepted 7 September 2015

Academic Editor: Ivo Caliò

Copyright (c) 2016 Guang-an Zhu et al. This is an open access article distributed under the Creative Commons Attribution License, which permits unrestricted use, distribution, and reproduction in any medium, provided the original work is properly cited.

\begin{abstract}
Fault slip burst is a serious dynamic hazard in coal mining. A static and dynamic analysis for fault slip was performed to assess the risk of rock burst. A numerical model FLAC ${ }^{3 \mathrm{D}}$ was established to understand the stress state and mechanical responses of fault rock system. The results obtained from the analysis show that the dynamic behavior of fault slip induced by stress waves is significantly affected by mining depth, as well as dynamic disturbance intensity and the distance between the stope and the fault. The isolation effect of the fault is also discussed based on the numerical results with the fault angle appearing to have the strongest influence on peak vertical stress and velocity induced by dynamic disturbance. By taking these risks into account, a stress-relief technology using break-tip blast was used for fault slip burst control. This technique is able to reduce the stress concentration and increase the attenuation of dynamic load by fracturing the structure of coal and rock. The adoption of this stress-relief method leads to an effective reduction of fault slip induced rock burst (FSIRB) occurrence.
\end{abstract}

\section{Introduction}

Rock burst, as one of the typical mining dynamic disasters, refers to the sudden failure of coal and rock under high stress. It can lead to extensive damage with serious consequences $[1,2]$. It is noted that rock bursts are more likely to occur in the case of mining or drivage around the fault, where the structure of coal and rock is more complex; a sudden roof fall and movement of the overlying strata will also facilitate fault slip induced by mining activities [3]. Specifically, the elastic energy generated by mining activities is transferred to the fault. Its sudden release has significant impact on the longwall panel and roadways. With the increase of mining depth and intensity, fault slip burst hazards are becoming increasing frequently in many countries including China [4].

Many attempts have been made to understand the mechanism of fault slip burst. Currently, various types of mechanical models for fault slip have been proposed by seismologists $[5,6]$. However, these studies do not demonstrate the significance of fault structure and rarely concern the effects of mining opening and strata movement on the fault. In recent years, studies have attempted to determine the relationship between extracting ore deposits and fault slip using theoretical analysis and numerical simulation. Sainoki and Mitri $[7,8]$ investigated the dynamic behavior of faults by means of FLAC ${ }^{3 \mathrm{D}}$ by considering various parameters, such as in situ stress and the mechanical properties of fault. The development of normal and shear stresses along the fault during the stoping process was determined by Jiang et al. [9]. Yan et al. [10] conducted statistical analysis of microseismic activity in the coal and rock of the fault area, based on the seismic data. The authors also concluded that, as the fully mechanized coal panel passes through the fault, the value of daily seismic energy release in the fault area increases steadily; the max energy tends to be rapidly increased.

The previously described mechanisms of fault slip mainly focused on the physical parameters of the fault plane and stress redistribution arising from mining activities, especially when mining comes near to the fault. However, dynamic response of fault slip induced by stress waves has rarely been investigated. As a matter of fact, fault slips have been shown to be closely related to seismic waves. On one hand, during the stress wave propagation process, the filling and locking of the fault show sharp shear, compression, and expansion, 
and even when they are broken, the friction on the fault is reduced. The normal stress of contact interfaces between rock and roof in elastic stage and elastic-plasticity stage decreases sharply under dynamic load, which is called anomalously low friction [11, 12]. On the other hand, the propagation and dynamic response of stress waves are influenced by the fault. The propagation characteristic of stress waves across jointed rock has been studied through theoretical analysis and numerical simulation by Song et al. [13] and Yang et al. [14]. Moreover, Wu and Cai [15] and Zhou et al. [16] have studied and illustrated the shock isolation and hanging wall effects of fractures.

In this paper, the mechanism of fault slip burst is outlined based on theoretical analysis and numerical modeling. A method of deep hole blasting is proposed for risk control of future dynamic disaster during subsequent mining activities around the fault. Finally, the methodology and results of a field trial of the proposed technique are also presented.

\section{The FSIRB Mechanism}

2.1. Rock Burst Induced by Static Stress Combined with Dynamic Load. A number of studies and field cases show that rock burst is induced by the tremor under the concentrated stress; that is, rock burst is induced by static stress combined with dynamic loads. It can be expressed as $[17,18]$

$$
\sigma_{j}+\sigma_{d} \geq \sigma_{b \min }
$$

where $\sigma_{j}$ is the static stress in the coal and rock mass; $\sigma_{d}$ is the dynamic stress induced by the tremor; and $\sigma_{b \min }$ is the critical stress required for rock burst. Equation (1) indicates that the higher the superposition of the static load in the coal and dynamic load induced by tremors, the more probability that rock bursts will occur.

This is also the principle of the fault slip burst induced by static and dynamic stress superposition, as shown in Figure 1.

2.2. High Static Stress. Research [19] shows that there is an area, where the vertical stress is increased to $2 \sim 3$ times more than the rock weight induced stress, near the fault. Due to the preexisting faults in front of the mining panel, the roof is discontinuous and reduces the ability to transfer the stress of overburden strata. As a result, stress concentration occurs in the pillar areas between the mining panel and the fault. Therefore, rock burst disasters happen frequently when mining activities approach the fault.

From analysis of the static stress in the fault pillar and roof strata fracture induced dynamic stress [20], the normal stress, shear stress along the fault, and the average static stress in the fault pillar can be derived. The results show that the high stress in the pillar increases as the mining panel approaches the fault; that is, the stress within the pillar rises with decreasing pillar width and increasing roof fracture length.

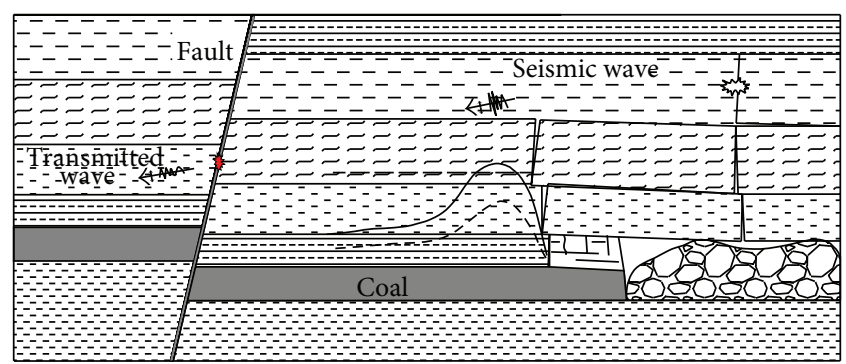

FIGURE 1: Sketch showing the mechanism associated with FSIRB.

2.3. Dynamic Stress. As described above, dynamic stress always originates from mining activities including roof breakage, the movement of overlying strata, coal and rock failure, and fault slip. These could also be termed as mine tremors.

2.3.1. Dynamic Behavior of Stress along the Fault. Based on the anomalously low friction effect, a theoretical block model of anomalously low friction rock burst was established by $\mathrm{Li}$ et al. [21], which showed that normal dynamic load on the interface of deep rock mass periodically changes under the vertical impulse load. Li et al. [22] also established the thinlayer interface model and corresponding wave propagation equation could be obtained from the analysis. Based on the abovementioned studies, it is concluded that, with stress wave propagation across the fault, the normal and shear stresses along the fault vary with time and the static friction changes to dynamic friction; thus rock burst will be induced easily.

\subsubsection{Attenuation Law of Stress Wave Propagation across} the Fault. The stress wave propagation will be reflected, refracted, and absorbed by the discontinuity such as a fault plane, and as a consequence part of the stress wave fails to pass through the fault. This is called the "isolation effect" [15].

$\mathrm{Li}$ and $\mathrm{Ma}[23,24]$ investigated stochastic seismic wave interactions with a slippery rock fault. The incident P- and Swave propagation law was analytically derived by considering many factors such as impinging angles and intensity of incident waves. There is a distinct difference between the interactions for different types of the incident waves. The P-waves will almost fully transmit across the fault without attenuation, whilst, in contrast, the S-waves are significantly affected by the fault.

\section{Numerical Analysis}

Fast Lagrangian Analysis of Continua in 3 Dimensions [25] was used to investigate the stress distribution and dynamic response of the fault during mining. The model assumes a length of $800 \mathrm{~m}$ in the strike direction, a width of $400 \mathrm{~m}$ in the dip direction, and a height of $130 \mathrm{~m}$, as shown in Figure 2(a).

Interface elements are used for the simulation of the fault plane; so as to make the fault slide, it should meet

$$
\frac{\tau}{\sigma_{N}}>\tan \varphi_{f}
$$


TABLE 1: Property parameters of the model.

\begin{tabular}{lcccccc}
\hline & Thickness $/ \mathrm{m}$ & Density $/\left(\mathrm{Kg} / \mathrm{m}^{3}\right)$ & Bulk $/ \mathrm{GPa}$ & Shear $/ \mathrm{GPa}$ & Cohesion $/ \mathrm{MPa}$ & Friction angle $/^{\circ}$ \\
\hline Overlying & 50 & 2500 & 1.31 & 0.42 & 0.30 & 33 \\
Main roof & 20 & 2700 & 2.30 & 1.52 & 1.70 & 38 \\
Immediate roof & 5 & 2500 & 1.31 & 0.42 & 0.30 & 33 \\
Coal & 5 & 1400 & 0.15 & 0.08 & 0.11 & 0.4 \\
Main floor & 50 & 2600 & 1.97 & 1.14 & & 35 \\
\hline
\end{tabular}

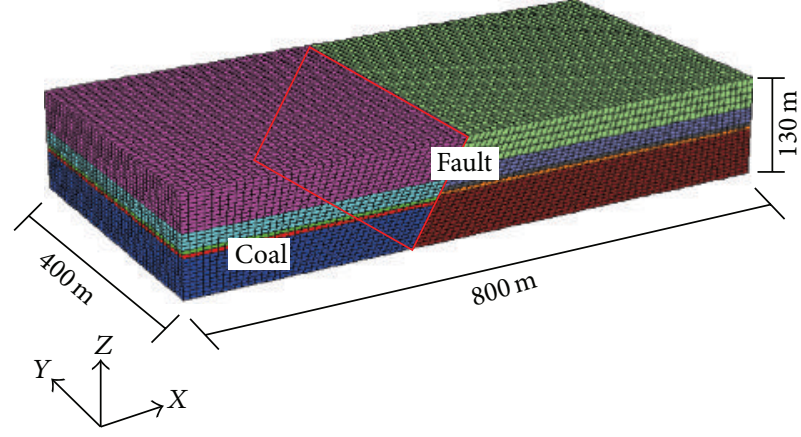

(a)

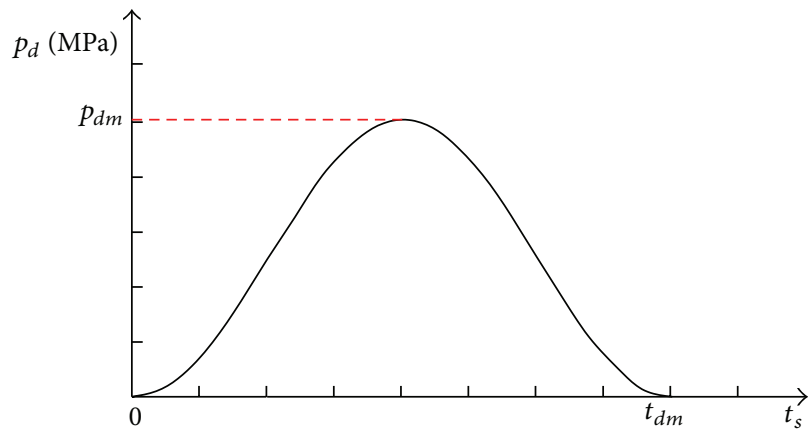

(b)

FIGURE 2: Basic model and fault location analyzed under combined static and dynamic loading. (a) Model setup. (b) The waveform of dynamic stress $p_{d}(t)$ with amplitude of $p_{d m}$ and duration of $t_{d m}$.

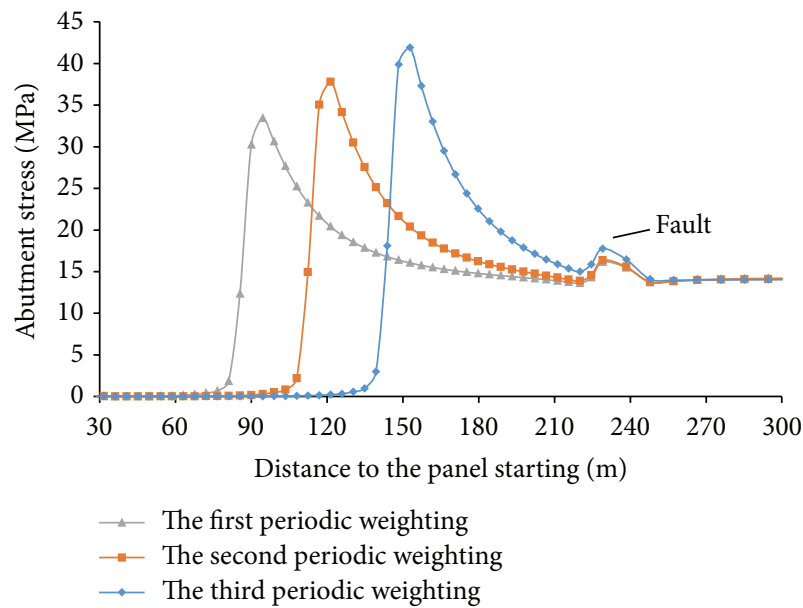

(a)

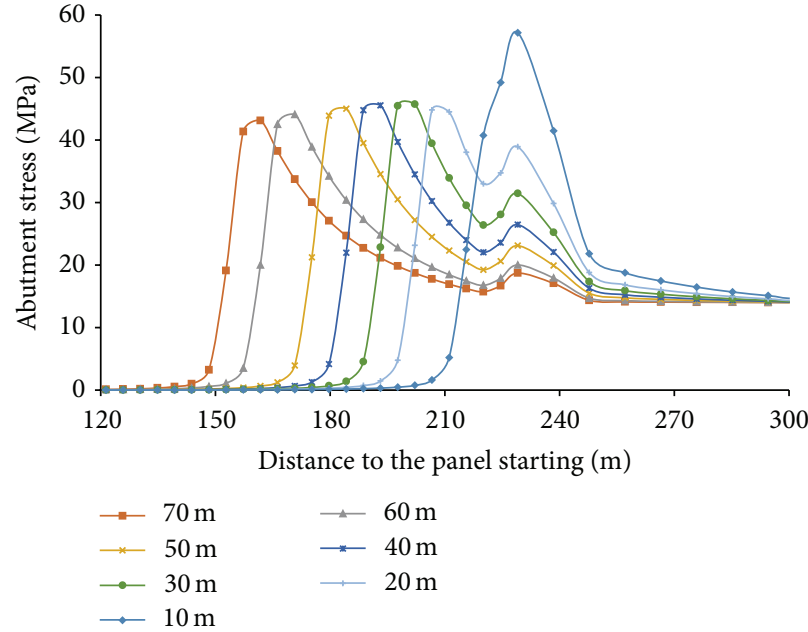

(b)

Figure 3: Abutment stress distribution of the panel along the strike: (a) during periodic weighting; (b) during mining in the fault area. Note that values in the boxes represent the distance between the panel and the fault.

where $\tau, \sigma_{N}$, and $\varphi_{f}$ represent shear stress, normal stress, and friction angle of the fault.

Table 1 shows the mechanical properties used in the model.

As regards the combined static and dynamic loading conditions (as defined in Figure 2(b)), the dynamic incident stress pulse, $p_{d}(t)$, is applied at the top surface of a model domain after the static boundary stresses are applied. Under the dynamic loading condition, the bottom surface of the domain that has been restrained during the static loading is free from stress. The half-sine stress pulse (as defined in Figure 2(b)) is used because this incident waveform is similar to the half-sine shape. For this waveform, two parameters (including amplitude $\left(p_{d m}\right)$ and duration $\left(t_{d m}\right)$ ) are involved in the numerical simulation in order to analyze the effect of the dynamic stress waveform on the fault slip.

During the simulation, the procedure below was followed.

Step 1. The peak mining-induced stress is calculated, which is formed when the mining panel comes close to the fault under static stress conditions. 


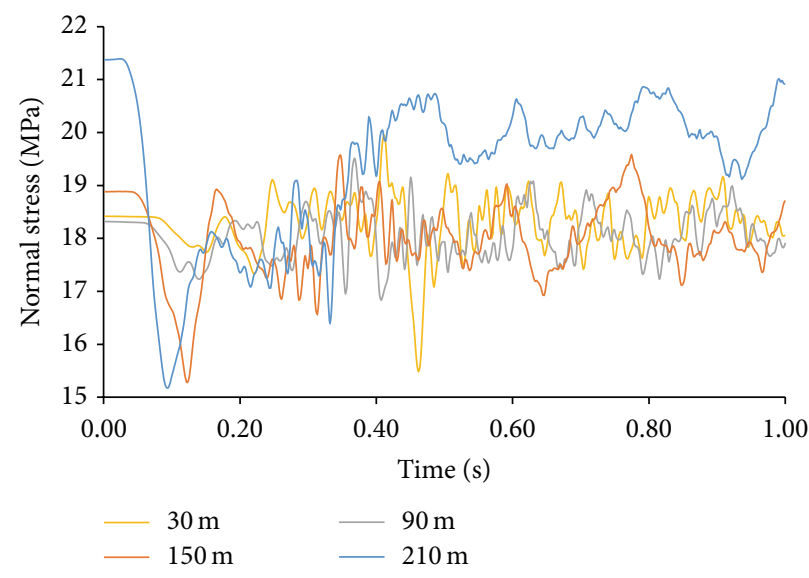

(a)

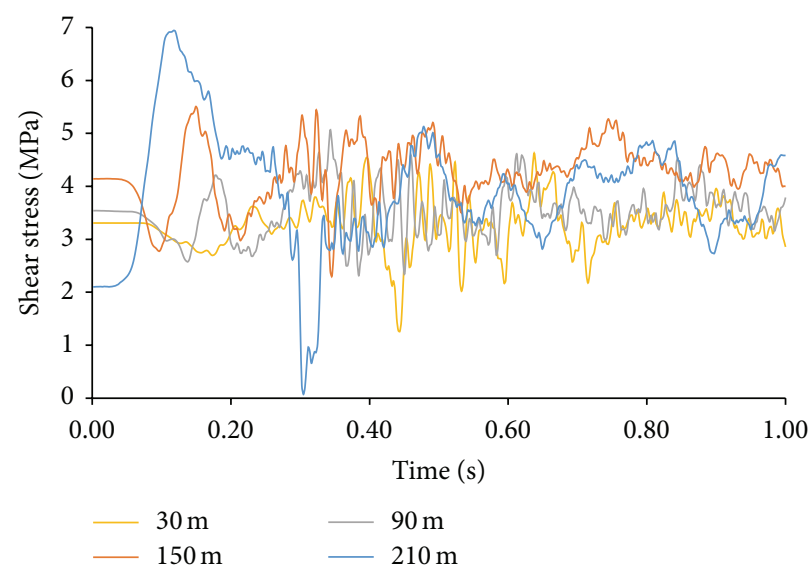

(b)

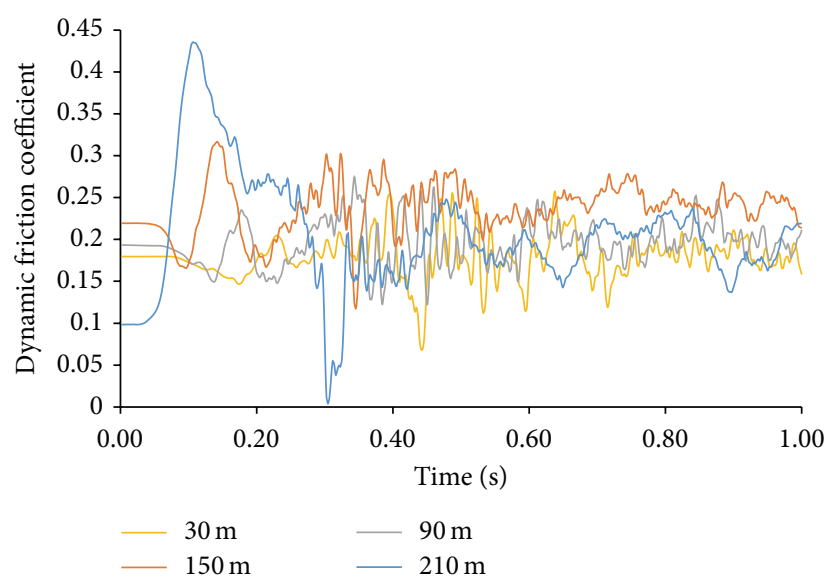

(c)

FIGURE 4: Stress evolution and dynamic friction coefficient along the fault at observation point ( $p_{d m}=30 \mathrm{MPa}$, depth = 500 m): (a) normal stress; (b) shear stress; and (c) dynamic friction coefficient. Note that values in the boxes represent the length of panel advance.

Step 2. The stress state and the stress wave propagation of the fault under dynamic disturbance are calculated.

Step 3. The burst-prone zones between the mining panel and the fault are determined.

3.1. Abutment Stress Distribution. The fault disrupts the distribution of the stress field which leads to significant discontinuity of the abutment stress. To understand the influence of mining-induced stress on the fault, the distance between the fault and mining panel was taken into account. Such distances were set as 70, 60, 50, 40, 30, 20, and $10 \mathrm{~m}$.

The abutment stress distribution during periodic weighting and mining around the fault in the panel along the centre line of mining panel is shown in Figure 3. Figure 3(a) indicates that the peak abutment stress occurs at a distance of $12 \mathrm{~m}$ and the coverage of mining-induced stress is about $50 \mathrm{~m}$ in front of the mining panel. The vertical stress barely varies, about $16 \mathrm{MPa}$, at the recorded point along the fault. These results suggest that, when the mining panel is far away from the fault, the peak abutment stress and the stress distribution remain almost constant. However, the stress concentration occurs on the fault which increases with a reduction of the distance between mining panel and the fault (from $70 \mathrm{~m}$ to $10 \mathrm{~m}$ ), as shown in Figure 3(b). The overstress along the fault recorded in these cases varies between 19 and $57 \mathrm{MPa}$; that is, stress increases of between $19 \%$ and $356 \%$ are produced. This implies that the smaller the distance between the mining panel and the fault, the greater the accumulation of compression produced.

3.2. Dynamic Mechanical State of the Fault. The dynamic module was used to investigate the response features of the fault under dynamic disturbance. The normal and shear stresses at the fault were applied to study dynamic behavior of fault slip induced by mining. The ratio between normal and shear stress was defined as the standard for evaluating the slip risk.

The stress evolution along the fault under dynamic analysis was recorded at the point close to the centre of mining panel: $y=200 \mathrm{~m}, z=60 \mathrm{~m}$. To avoid the damage and failure 

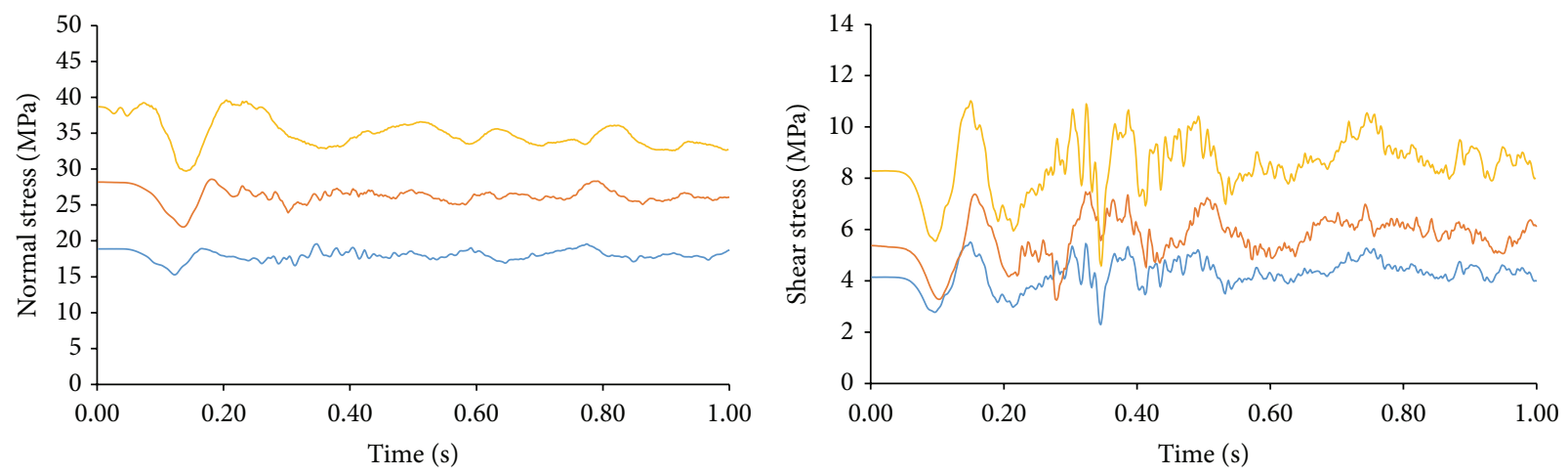

Mining depth:
$-500 \mathrm{~m}$
$-800 \mathrm{~m}$
$1000 \mathrm{~m}$

Mining depth:

$-500 \mathrm{~m}$

$-800 \mathrm{~m}$

$1000 \mathrm{~m}$

(a)

(b)

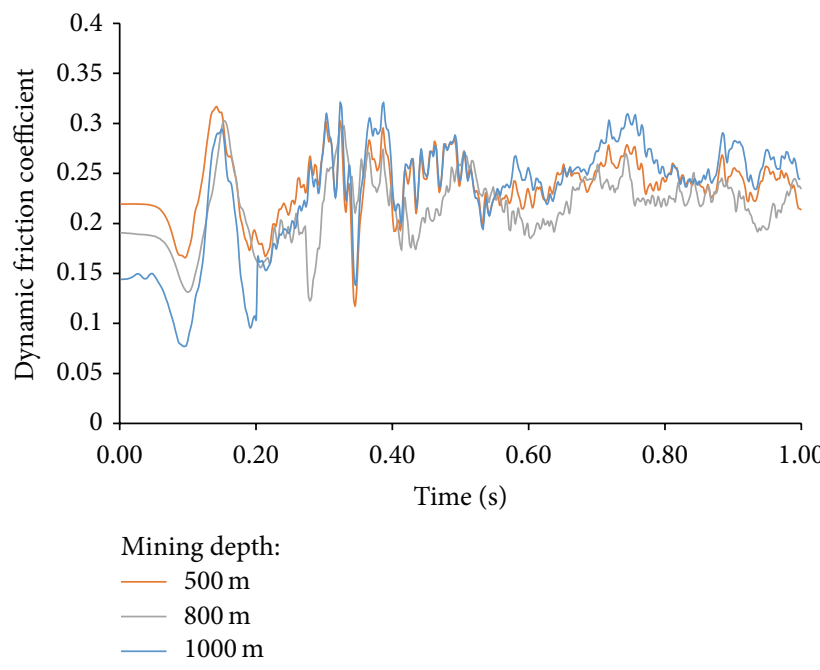

(c)

FIGURE 5: Stress evolution under dynamic disturbance in different depths ( $p_{d m}=30 \mathrm{MPa}$, depth $\left.=500 \mathrm{~m}\right)$ : (a) normal stress; (b) shear stress; and (c) dynamic friction coefficient.

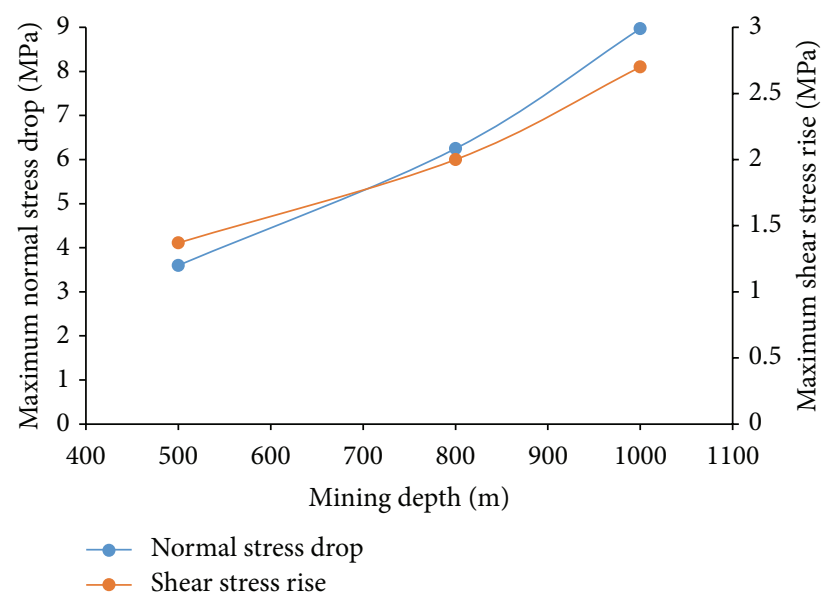

FIgURE 6: Effect of mining depth on the change in normal and shear stresses along the fault. of the model, the amplitude of the dynamic disturbance $\left(p_{d m}\right)$ was specified as $30 \mathrm{MPa}$ (with a time duration $\left(t_{d m}\right)$ of $0.2 \mathrm{~s}$ ).

3.2.1. Effect of Mining Panel Advance. The change rules for normal and shear stresses varying with time are given in Figure 4 . It can be seen that the average period of dynamic load effect is about $0.2 \mathrm{~s}$. There is a clear difference in the stress variation as normal stress at the point gradually decreases from 21.4 MPa to 15.2 $\mathrm{MPa}$, whilst shear stress increases from 2.1 $\mathrm{MPa}$ to $6.9 \mathrm{MPa}$, leading to a rise of the dynamic friction coefficient. Considering the distance between the mining panel and the fault, when the distance is less than $70 \mathrm{~m}$, the stresses along the fault change much more. This indicates that the dynamic behavior of fault slip is sensitive to the distance and it can therefore be concluded that, as mining operation proceeds, the dynamic response of fault slip induced by mining activities becomes increasingly violent. 


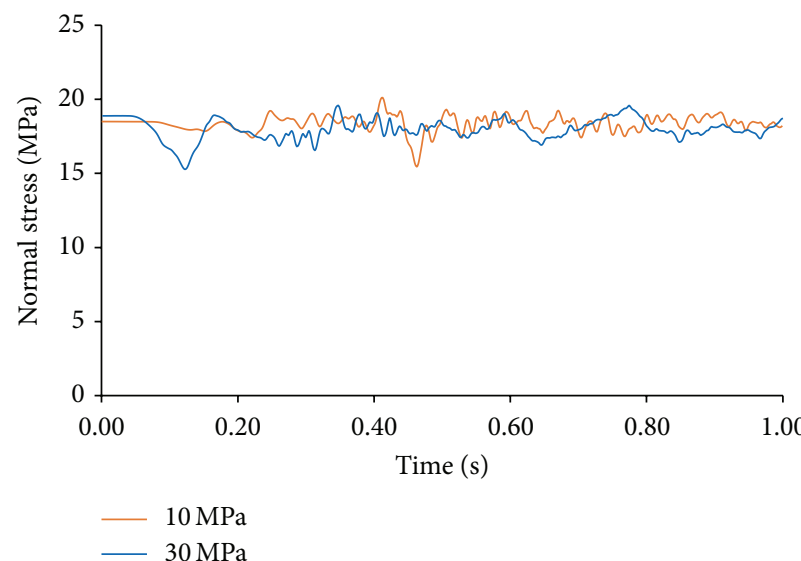

(a)

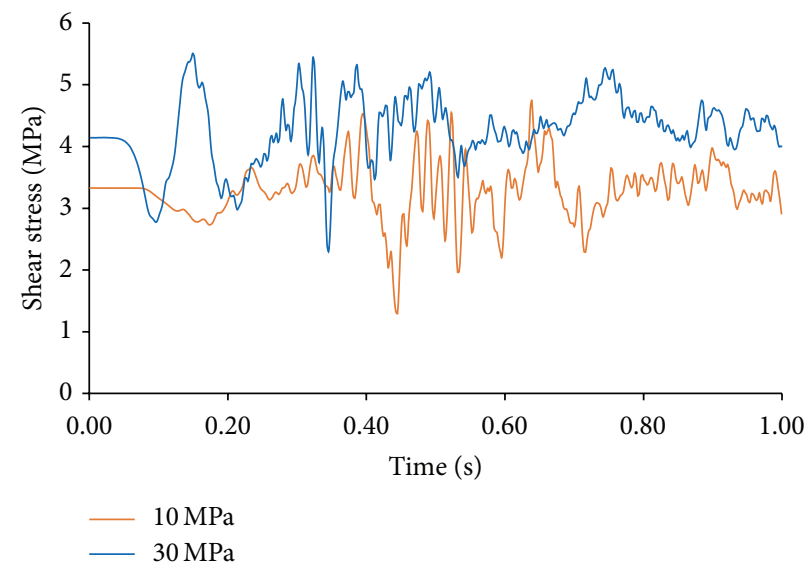

(b)

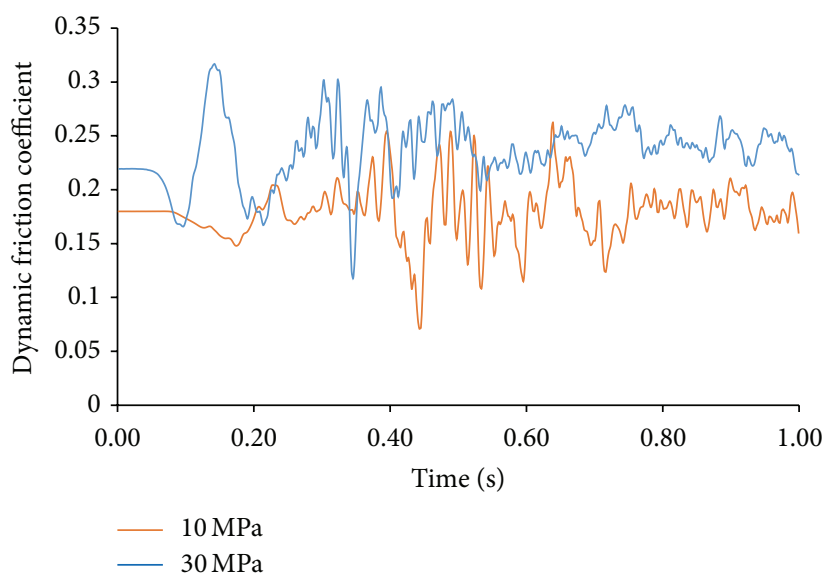

(c)

FIGURE 7: Stress evolution under different stress wave intensity (depth $=500 \mathrm{~m})$. Note that values in the boxes represent the amplitude of the dynamic disturbance $\left(p_{d m}\right)$.

3.2.2. Effect of Mining Depth. The model, initially calculated for a depth of around of $500 \mathrm{~m}$, was therefore recalculated for depths of $800 \mathrm{~m}$ and $1000 \mathrm{~m}$. Figure 5 shows the results obtained for the models at different depths. As for the effect of mining depth, it is evident from Figure 5 that there are clear relationships between the change in normal and shear stresses of the fault. To better understand these relationships, the detailed data are plotted in Figure 6. It can be seen that, with increasing mining depth, the stress drop of normal stress increases from 3.60 MPa to $8.97 \mathrm{MPa}$, and the stress rise of shear stress increases from $1.37 \mathrm{MPa}$ to $2.70 \mathrm{MPa}$. These results suggest that the influence of mining depth is remarkable in that the mining depth is proportional to the stress drop of normal stress and the stress rise of shear stress.

3.2.3. Effect of Dynamic Disturbance Intensity. The change in stresses along the fault for different dynamic intensities is shown in Figure 7. It can be seen that the dynamic intensity has a large influence on the evolution of stress.

At the specific value of mining depth $(500 \mathrm{~m})$, with the increase of the amplitude of dynamic disturbance intensity, the recorded stresses varies greatly. When $p_{d m} \leq 10 \mathrm{MPa}$, the stress drop of normal stress is almost zero as the stability of the fault does not change; that is, the dynamic behavior can be considered elastic as fault slip burst in this case is more impossible to occur. When $p_{d m}>10 \mathrm{MPa}$, stresses change greatly with the increasing of dynamic intensity.

Thus, it can be seen from Sections 3.2.2 and 3.2.3 that mining depth and dynamic stress wave intensity can be two of the most important factors determining the dynamic behavior of fault slip.

3.2.4. Effect of Fault Angle. In this section, 21 monitoring points were set up at the bottom of the model $(x=$ $230-420 \mathrm{~m}, y=200 \mathrm{~m}$, and $z=20 \mathrm{~m}$ ), as shown in Figure 8(a). These were used to observe the dynamic response of vertical stress and velocity. Figures $8(\mathrm{~b})$ and 8 (c) show that the second stress redistribution occurs after underground mining activities, which make the curves more complex. However, it basically presents the same rule, the dynamic response of the vertical stress and velocity are anomalous in front of the mining panel, and stress concentration is not obvious at the floor. When the fault angle is $60^{\circ}$, the peak 


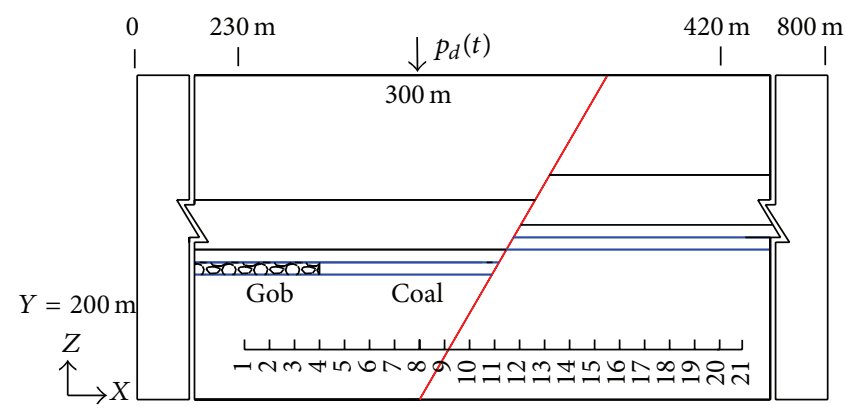

(a)

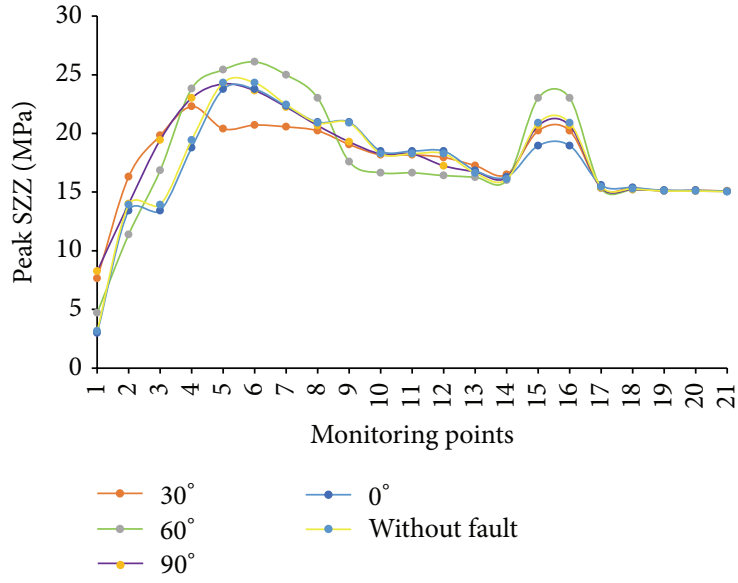

(b)

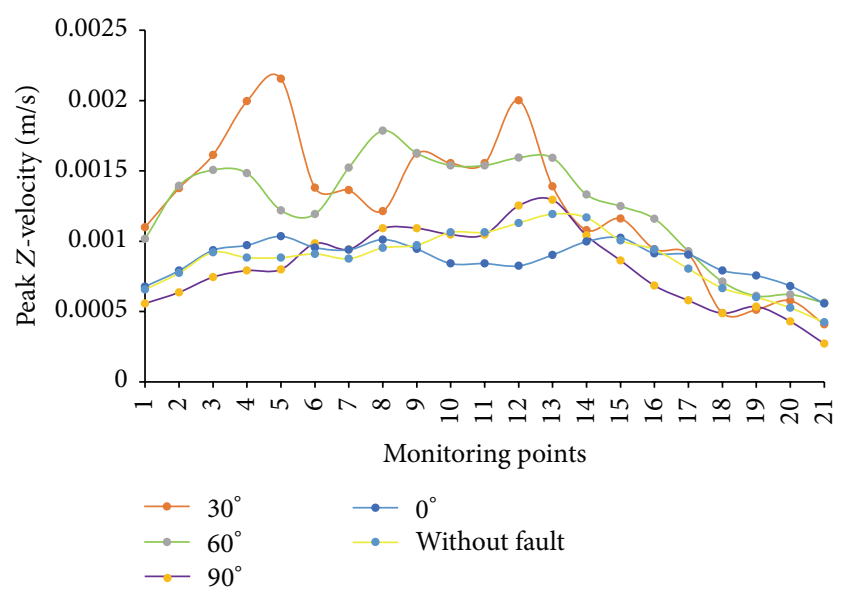

(c)

FIGURE 8: Curves of peak vertical stress and velocity of monitoring points: (a) monitor locations; (b) peak SZZ; and (c) peak $Z$-velocity.

values of vertical stress and velocity reach maximums of $23.02 \mathrm{MPa}$ and $0.0012 \mathrm{~m} / \mathrm{s}$, respectively. When the fault angle is $90^{\circ}$, the isolation effect on stress waves is not obvious, and the incident stress waves are almost fully transmitted though the fault.

According to the above analysis, the following conclusions can be drawn. The dynamic response of the vertical stress and velocity beside the fault are anomalous compared with that on the fault, and the dynamic response of the coal and rock on the side of seismic source will be more serious than that on the other side. With the increasing of fault angles from $0^{\circ}$ to $90^{\circ}$, the isolation effect of the fault on stress waves firstly increases and then decreases.

3.2.5. Isolation Effect of the Fault. Similarly, a series of monitoring points were set to investigate the isolation effect of the fault, as shown in Figure 9(a). Figures 9(b) and 9(c) show the propagation and response of stress waves that are influenced by the fault. The stress waves attenuate exponentially with increases in distance to the seismic source. They vibrate at the beginning and then quickly attenuate with the amplitude decreasing significantly after $30 \mathrm{~m}$ and becoming very weak after $90 \mathrm{~m}$. However, as the stress waves propagate across the fault, the amplitude shows a further attenuation. These results imply that the fault makes only a part of the energy transmit, which leads to an obvious energy attenuation, while the friction on the fault will also absorb a part of energy.

\section{Control FSIRBs}

Based on the study of the FSIRB mechanism and analysis of the numerical model, it can be concluded that fault slip bursts can be controlled by the following detailed methods:

(1) Avoidance of high stress concentration is achieved. It provides the stress basis for rock burst induced by the dynamic load. Thus, some measures should be adopted to reduce the stress concentration such as large diameter drilling and destress blasting in the coal seam.

(2) Avoid the formation of strong tremors to eliminate high dynamic load and presplit the roof above the coal seam to reduce the dynamic load.

(3) Based on static and dynamic stress superposition, techniques can be used to induce rock burst artificially and release the elastic strain energy accumulated in coal and rock and reduce the stress concentration and prevent dynamic disaster induced by rock burst. 


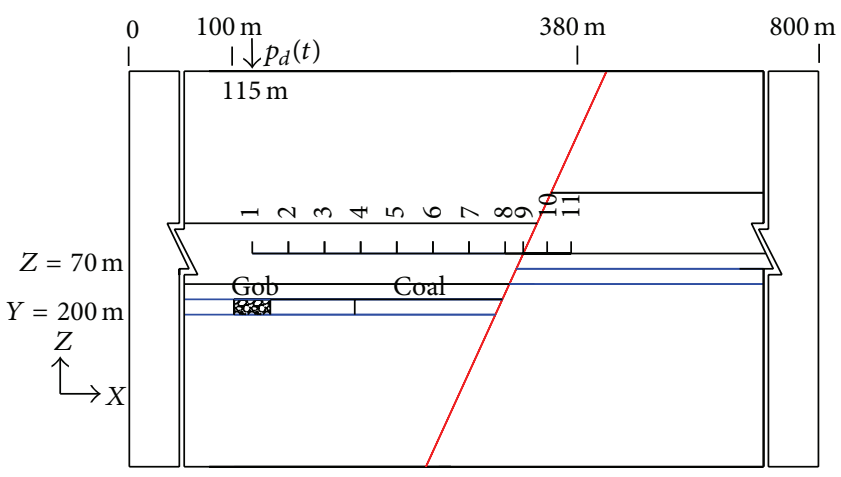

(a)

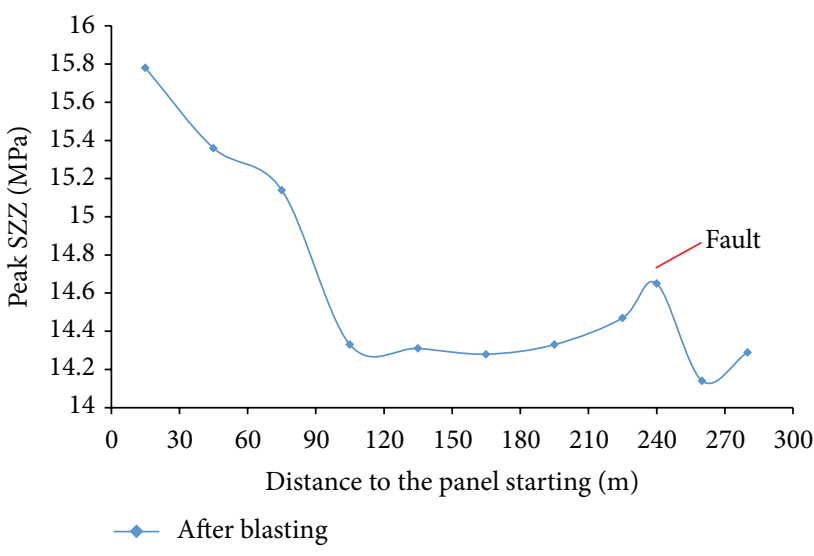

(b)

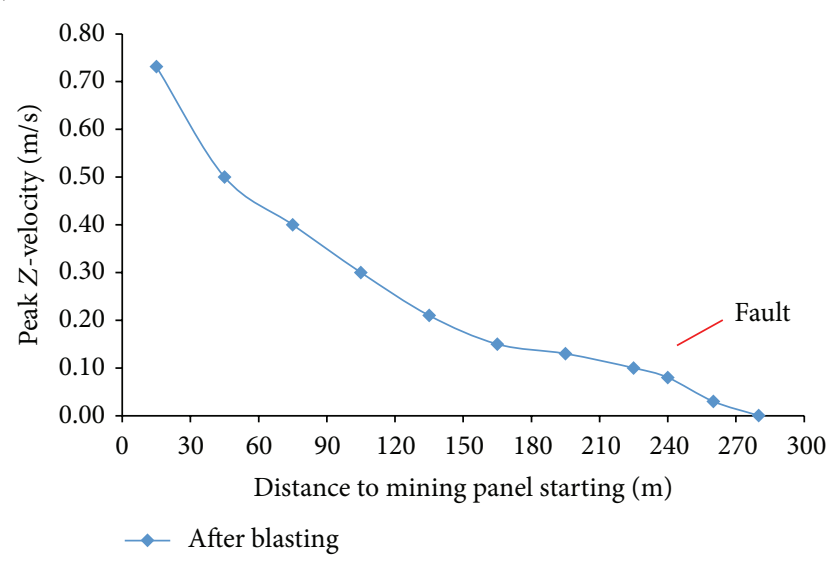

(c)

Figure 9: Vertical stress and velocity attenuating curve of stress wave $\left(p_{d m}=30 \mathrm{MPa}\right.$, depth $\left.=500 \mathrm{~m}\right)$ : (a) monitor locations; (b) peak SZZ; and (c) peak $Z$-velocity.

4.1. Technique of Break-Tip Blast (BTB). To mitigate rock burst risk during mining activities in the fault area, based on the mining condition of panel 3206, the application of the BTB method had been proposed for dynamic disaster control.

The primary aim of BTB is to control rock burst by fracturing the structure of coal and rock, so as to reduce the stress concentration and increase the attenuation of dynamic load. In China, previous BTB trials have been reported to handle the thick and hard roof which is often difficult to cave $[26,27]$.

However, few research studies or field trials have evaluated the efficacy of BTB to control fault slip bursts in coal mining, particularly as the mining technological conditions and geological structure are complex.

4.2. Stress Analysis and Stress Waves Propagation before and after Blasting. The essence of the BTB technique is to reduce the intensity of rock in local area. FLAC ${ }^{3 \mathrm{D}}$ can change the parameters of the model material. The mechanical parameters of rock mass in the crushed zone should be decreased to one-fifth of the original during calculation of the stress state of surrounding rock after blasting [28].

In this section, the monitor locations are consistent with those in Sections 3.1 and 3.2.5. The BTB method was implemented at a distance of $5 \mathrm{~m}$ in front of the fault. Figure 10 shows the stress distribution in the roof before and after blasting when the mining panel comes near to the fault. The mining-induced stress of the fault is much lower after blasting than before blasting, decreased from $38.06 \mathrm{MPa}$ to 33.02 MPa (Figure 10(b)). This leads to a value for stress drop of $13 \%$, indicating that more effective stress relief is obtained after blasting.

Lastly, the isolation effect of the fault before and after blasting is shown in Figure 11. The difference in dynamic response of the fault between the two models is not obvious, the peak value of vertical stress drop is only $0.2 \mathrm{MPa}$, and the peak value of vertical velocity drop is only $0.05 \mathrm{~m} / \mathrm{s}$. This is because the above analysis concerns the simulated results of a single hole. So, it can be concluded that the effect of pressure relief will be more evident, after a group of blast holes being cut.

\section{Field Trial of Fault Blasting}

5.1. Site Description. The selected coal panel is in the Chaoyang Coal Mine in Shandong Province, China. Longwall mining with sublevel caving technology was adopted for the underground mining of number 3 coal seam, whose 


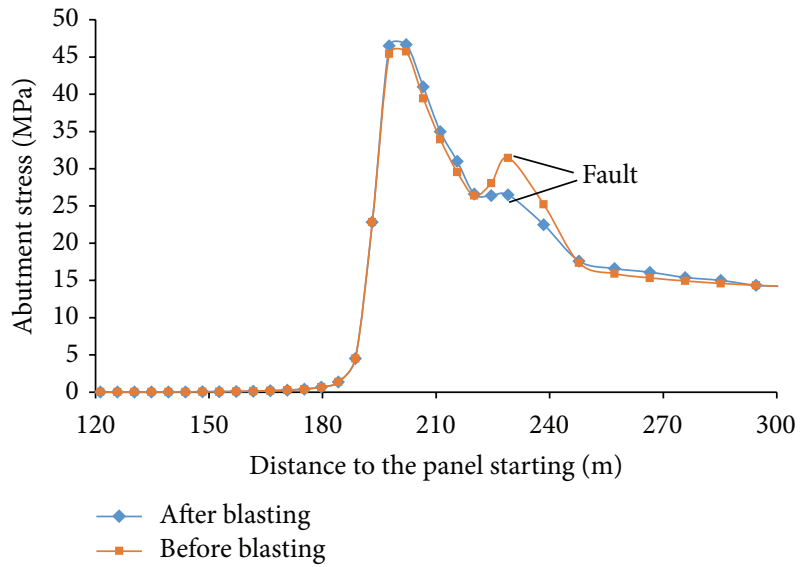

(a)

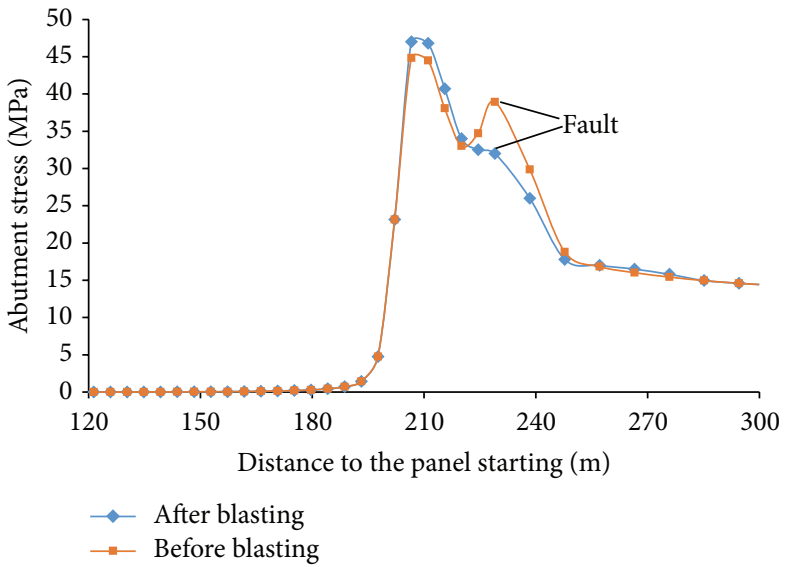

(b)

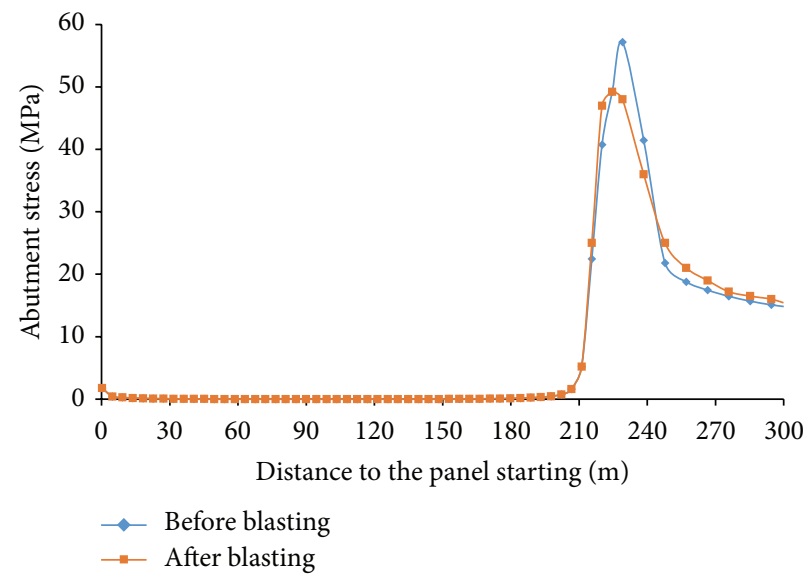

(c)

FIGURE 10: Vertical Stress distribution with different distances between mining panel and the fault before and after blasting $\left(p_{d m}=30 \mathrm{MPa}\right.$, depth $=500 \mathrm{~m}$ ): (a) the distance is $30 \mathrm{~m}$; (b) the distance is $20 \mathrm{~m}$; and (c) the distance is $10 \mathrm{~m}$.

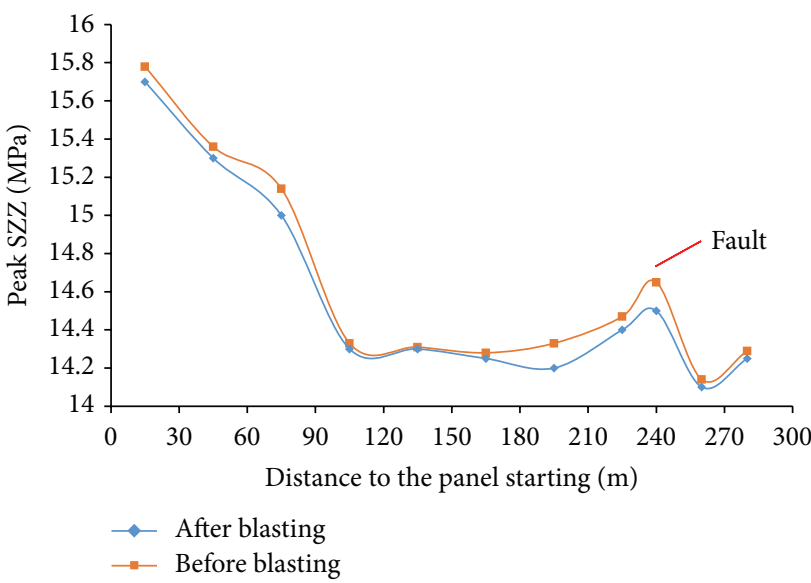

(a)

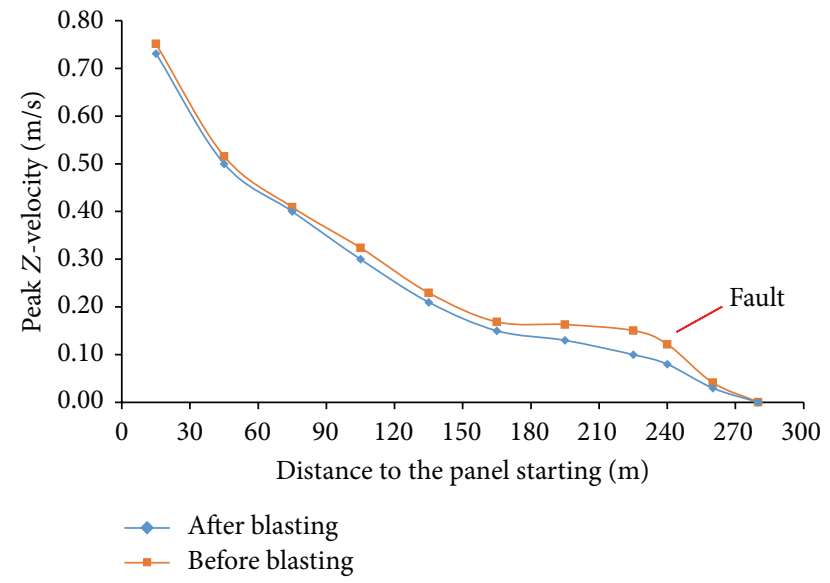

(b)

FIGURE 11: Isolation effect of the fault before and after blasting. 


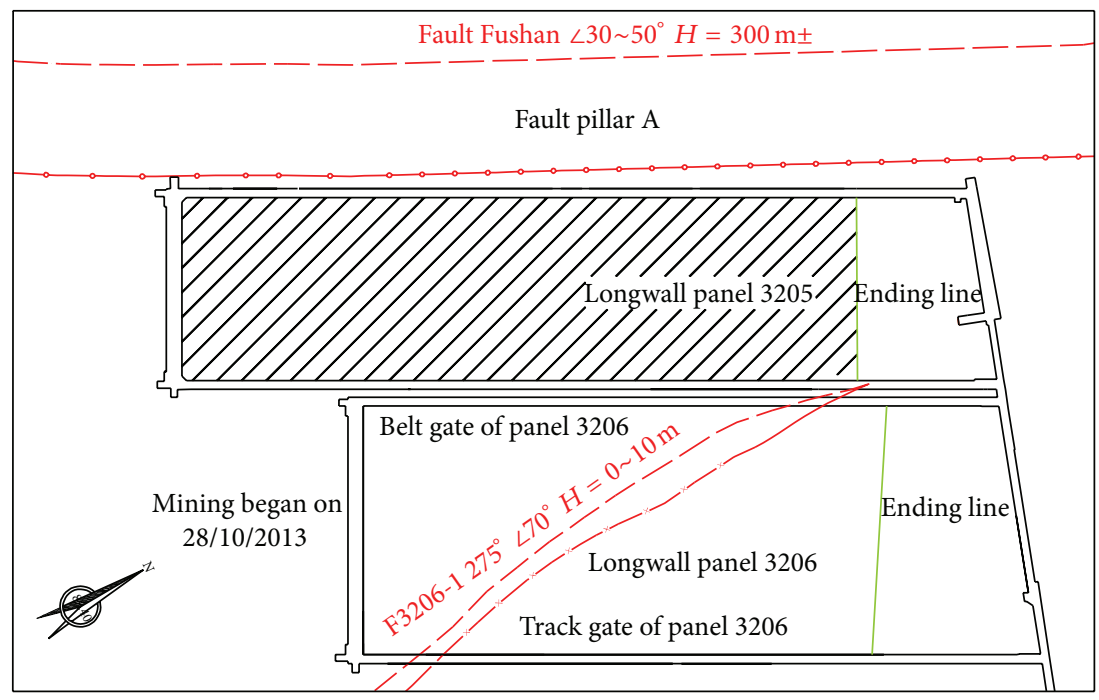

FIGURE 12: Gateway layout of the mining 3206 area.

thickness varies from 2 to $7.5 \mathrm{~m}$. The main strata configuration is uniclinal with an average angle of $16^{\circ}$. The cover depth of number 3 coal seam is about $900 \mathrm{~m}$ which is in high risk of rock burst. The roof strata are mainly composed of silt and fine sandstone with a thickness of $5-15 \mathrm{~m}$.

Plan view of the 3206 mining district is illustrated in Figure 12, and panel 3205 is situated next to panel 3206 in the northwest. The length of longwall panel 3206 is $303 \mathrm{~m}$ and its width is $111 \mathrm{~m}$. The mining in this panel began on October 28, 2013, and was completed on July 29, 2014.

In the northwest, lies fault Fushan (fault throw is about $300 \mathrm{~m}$ and fault inclination varies from $30^{\circ}$ to $50^{\circ}$ ) and the distance between panel 3206 and the fault is about $100 \mathrm{~m}$. A small fault F3206-1 situates in the middle of the panel. The other parts of the area next to panel 3206 are not extracted.

5.2. Monitoring Measures. The Poland SOS system was installed in the Chaoyang Coal Mine. The system is comprised of signal acquisition station, recorder system, and analyzer system in primary station on the ground and detection probes underground. Detection probes receive the electric signal transformed by speed signal of coal and rock shock initially before transferring to primary station on the ground via the communication cable. The signal is collected, enlarged, and transferred according to the signal acquisition station. Then, the signals are recorded and saved by the recorder system. Finally, the analyzer system is used to analyze and calculate the location of mine tremors and their energy.

5.3. Preventative Measures and Their Effects. To weaken the effect of dynamic stress induced by the first weighting and fault activation, a group of BTB holes were added at the track gate. The schematic diagram (of both the section and

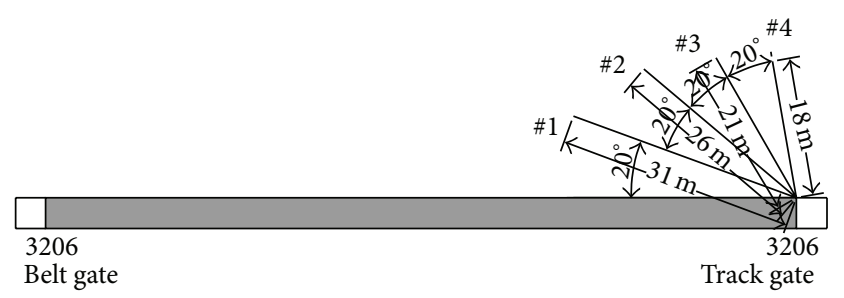

FIGURE 13: Schematic of the break-tip blasting (BTB) technique in the study area.

the plan) of the adopted design for the BTB in the panel is illustrated in Figure 13. All of the boreholes were drilled upwards at angles between $20^{\circ}$ and $70^{\circ}$; the borehole lengths varied from $18 \mathrm{~m}$ to $31 \mathrm{~m}$.

The seismic monitoring in longwall panel 3206 provided a map of the recorded seismic events, along with a summary graph of the recorded seismic energy in the area of the longwall panel. Figures 14 and 15 show plots of the recorded seismic activity with respect to the longwall drivage, advance, and the break-tip blasting around the fault in panel 3206 . The seismic activity is predominantly recorded from three areas: Fault Fushan, Fault 3206-1, and parts of mining panel beside the gob. The statistical results showed that the recorded seismic activity is sensitive to the fault in the panel. After taking the BTB method, the number of seismic events with high energy levels (>1000 J) was dramatically lower (blue and yellow ellipses in Figures 15(a) and 15(b)) in the 240-day mining period (October 28, 2013, to February 18, 2014) than in the 204-day driving period (February 2, 2013, to September 16, 2013). Continuous observations of the recorded seismic activity with respect to the mining progress in the panel showed that the break-tip blasting effectively controlled the fault activation. 


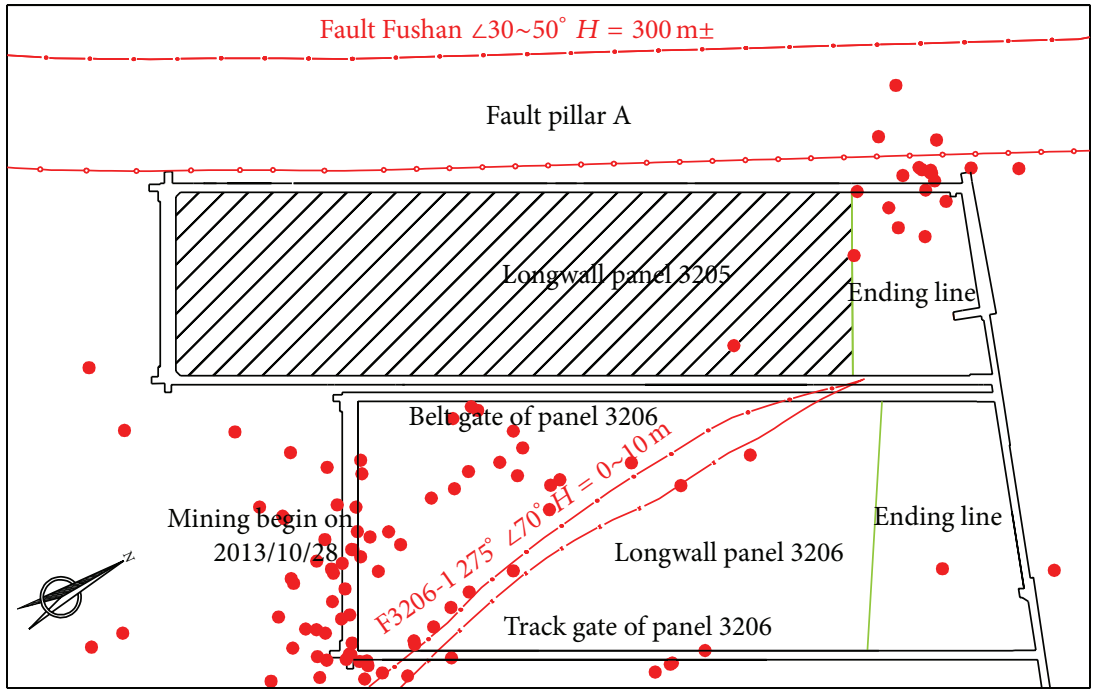

(a)

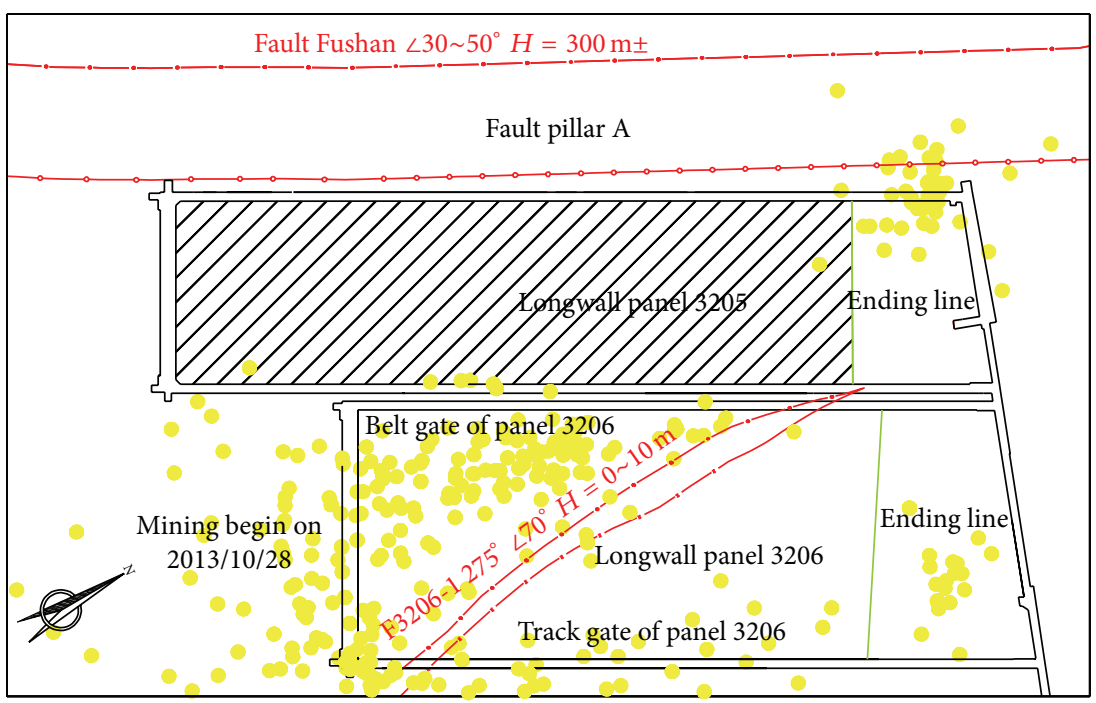

(b)

FIGURE 14: Seismic activity recorded during longwall drivage-localization map of recorded seismic events from February 2, 2013, to September 16, 2013. (a) 1000 to $10000 \mathrm{~J}$; (b) >10000 J.

\section{Conclusion}

In this paper, static stress analysis and dynamic response were conducted to investigate the influence of the distance between the mining panel and fault, mining depth, dynamic disturbance intensity, and fault angle on fault slip induced by stress waves. Numerical models considering the above factors were generated by FLAC ${ }^{3 \mathrm{D}}$ software. It can be concluded that mining depth and dynamic disturbance intensity have strong influences on the stress change along the fault. Similarly, normal stress drop and shear stress rise due to mining increases with decreasing distance between the mining panel and fault. Also, the attenuation law of stress wave propagation across the fault was investigated. The isolation effect is shown to firstly increase and then decrease with the increasing fault angle from $0^{\circ}$ to $90^{\circ}$. As seen from the field trail, adopted design of the break-tip blasting also reduces the range and the amount of mining induces stress concentration around the fault.

\section{Conflict of Interests}

The authors declare that there is no conflict of interests regarding the publication of this paper.

\section{Acknowledgments}

This work was supported and financed by the Research and Innovation Project for College Graduates of Jiangsu 


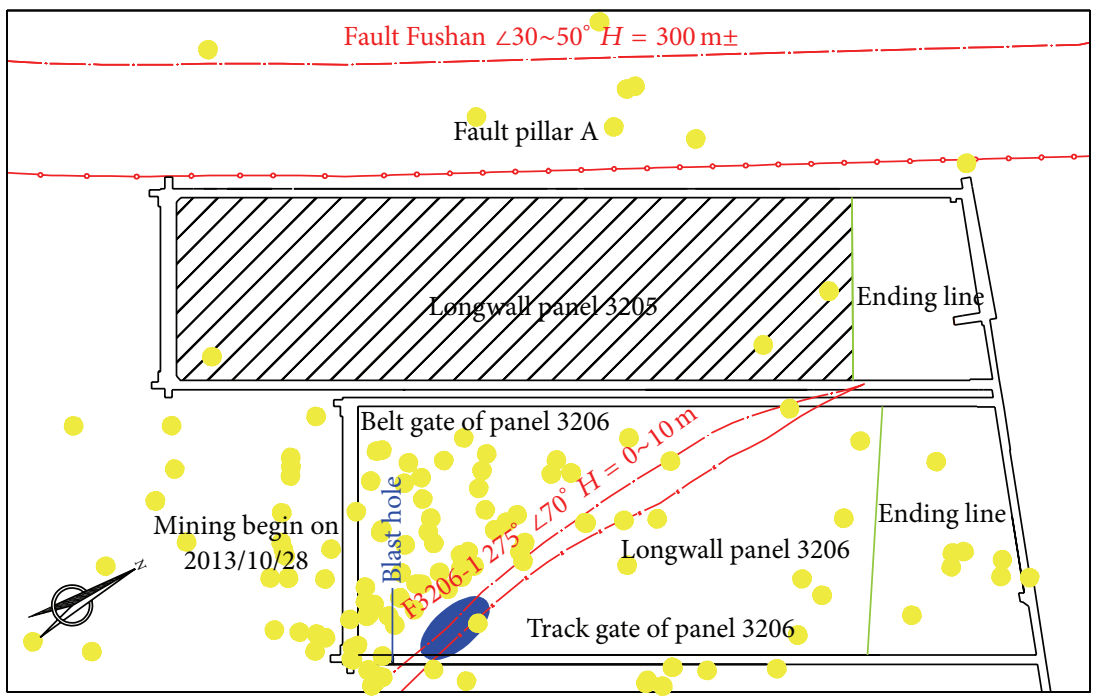

(a)

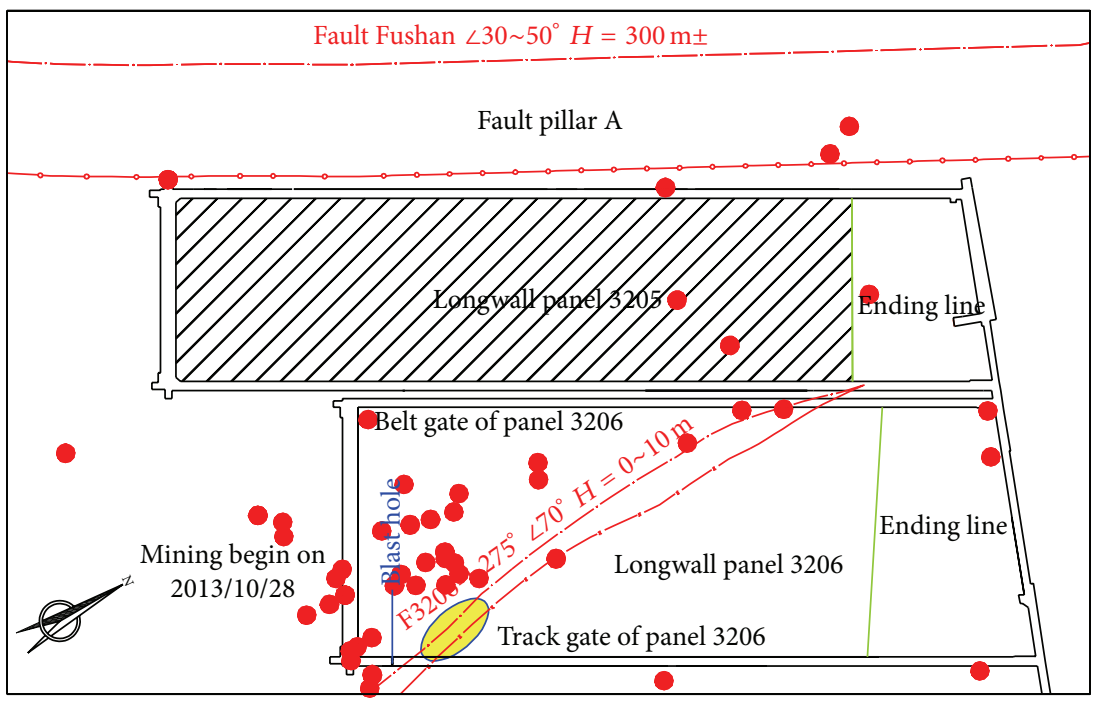

(b)

FIGURE 15: Seismic activity recorded during longwall advance-localization map of recorded seismic events from October 28, 2013, to February 18, 2014. (a) 1000 to $10000 \mathrm{~J}$; (b) >10000 J.

Province (no. CXZZ12_0949), the National Natural Science Foundation of China and the Shenhua Group Corporation Limited (no. 51174285), the Fundamental Research Funds for the Central Universities (no. 2014XT01), and the Priority Academic Program Development of Jiangsu Higher Education Institutions (no. SZBF2011-6-B35).

\section{References}

[1] L.-M. Dou and X.-Q. He, Theory and Technology of Rock Burst Prevention, China University of Mining and Technology Press, Xuzhou, China, 2001.

[2] L.-M. Dou, C.-G. Zhao, and S.-G. Yang, Prevention and Control of Rock Burst in Coal Mine, China University of Mining and Technology Press, Xuzhou, China, 2006.
[3] Z.-H. Li, Research on rockburst mechanism induced by fault slip during coal mining operation [Ph.D. thesis], China University of Mining and Technology, Xuzhou, China, 2009.

[4] W. Cai, L.-M. Dou, A.-Y. Cao, S.-Y. Gong, and Z.-L. Li, "Application of seismic velocity tomography in underground coal mines: a case study of Yima mining area, Henan, China," Journal of Applied Geophysics, vol. 109, pp. 140-149, 2014.

[5] J. Ma, S.-L. Ma, L.-Q. Liu, Z.-H. Deng, W.-T. Ma, and T.-C. Liu, "Geometrical textures of faults, evolution of physical field and instability characteristics," Acta Seismologica Sinica, vol. 9, no. 2, pp. 261-269, 1996.

[6] P.-E. Li and Y.-Q. Yin, "An instability model for fault earthquake genesis and occurrence," Chinese Journal of Geophysics, vol. 57, no. 1, pp. 157-166, 2014.

[7] A. Sainoki and H. S. Mitri, "Dynamic behaviour of mininginduced fault slip," International Journal of Rock Mechanics and Mining Sciences, vol. 66, pp. 19-29, 2014. 
[8] A. Sainoki and H. S. Mitri, "Dynamic modelling of fault-slip with Barton's shear strength model," International Journal of Rock Mechanics and Mining Sciences, vol. 67, pp. 155-163, 2014.

[9] Y.-D. Jiang, T. Wang, Y.-X. Zhao, and C. Wang, "Numerical simulation of fault activation pattern induced by coal extraction," Journal of China University of Mining \& Technology, vol. 42, no. 1, pp. 1-5, 2013.

[10] X.-L. Yan, X.-H. Chen, and X.-Y. Yan, "Analysis on microseismic law when full-mechanized coal pane passes through fault," Journal of China Coal Society, vol. 36, supplement 1, pp. 83-87, 2011.

[11] M. V. Kurlenya, V. V. Adushkin, and V. N. Oparin, "Alternatingreaction of rocks to dynamic action," Doklady. ANSSSR Geotechnics, vol. 26, no. 2, pp. 323-329, 1992.

[12] M.-Y. Wang, Z.-P. Zhou, and Q.-H. Qian, “Tectonic, deformation and failure problems of deep rock mass," Chinese Journal of Rock Mechanics and Engineering, vol. 25, no. 3, pp. 448-455, 2006.

[13] L. Song, Z.-S. Shao, and M.-Z. Wu, "Theoretical analysis on propagation characteristic of stress waves in jointed rock," Journal of China Coal Society, vol. 36, supplement 2, pp. 241246, 2011.

[14] F.-W. Yang, H.-B. Li, J.-C. Li, Y.-F. Hao, and M. Wang, "Numerical simulation of transmission characteristic of oblique incidence of stress waves across linear elastic joints," Rock and Soil Mechanics, vol. 34, no. 3, pp. 901-907, 2013.

[15] S.-W. Wu and Z.-Y. Cai, "Preliminary study on fault isolation effect," in Proceedings of the 3th National Academic Conference on Rock Dynamic, Guilin, China, 1992.

[16] J. Zhou, L.-Q. Zhang, R.-L. Hu, and X.-L. Wang, "Study of rules of stress waves propagation under various attitudes of larfe-scale fractures," Chinese Journal of Rock Mechanic and Engineering, vol. 30, no. 4, pp. 769-780, 2011.

[17] L.-M. Dou, Z.-L. Mu, Z.-L. Li, A.-Y. Cao, and S.-Y. Gong, "Research progress of monitoring, forecasting, and prevention of rockburst in underground coal mining in China," International Journal of Coal Science \& Technology, vol. 1, no. 3, pp. 278288, 2014

[18] Z.-L. Li, L.-M. Dou, G.-F. Wang, W. Cai, J. He, and Y.-L. Ding, "Risk evaluation of rock burst through theory of static and dynamic stresses superposition," Journal of Central South University of Technology, vol. 22, no. 2, pp. 676-683, 2015.

[19] C.-Q. Nan and X.-T. Feng, "Simplified tectonic stress model and analytical solution for concave-circular-arc fault," Chinese Journal of Rock Mechanics and Engineering, vol. 23, no. 23, pp. 3984-3989, 2004.

[20] Z.-L. Li, L.-M. Dou, W. Cai et al., "Investigation and analysis of the rock burst mechanism induced within fault-pillars," International Journal of Rock Mechanics \& Mining Sciences, vol. 70, pp. 192-200, 2014.

[21] J.-C. Li, H.-B. Li, Y.-Y. Jiao, Y.-Q. Liu, X. Xia, and C. Yu, "Analysis for oblique wave propagation across filled joints based on thinlayer interface model," Journal of Applied Geophysics, vol. 102, pp. 39-46, 2014.

[22] L.-P. Li, Y.-S. Pan, X.-C. Wang, and J.-P. Tang, "Influence analysis of exploit depth and vertical impact load on anomalously low friction rockburst," Chinese Journal of Rock Mechanic and Engineering, vol. 33, supplement 1, pp. 3225-3230, 2014.

[23] J.-C. Li and G.-W. Ma, "Analysis of blast wave interaction with a rock joint," Rock Mechanics and Rock Engineering, vol. 43, no. 6, pp. 777-787, 2010.
[24] J.-C. Li, G.-W. Ma, and J. Zhao, "Analysis of stochastic seismic wave interaction with a slippery rock fault," Rock Mechanics and Rock Engineering, vol. 44, no. 1, pp. 85-92, 2011.

[25] Itasca Consulting Group Inc, FLAC3D Fast Lagrangian Analysis of Continua in 3 Dimensions User's Guide, Itasca Consulting Group Inc, Minneapolis, Minn, USA, 2005.

[26] Q.-X. Qi, Y. Lei, H.-Y. Li et al., "Theory and application of prevention of rock burst by break-tip blast in deep hole," Chinese Journal of Rock Mechanics and Engineering, vol. 26, supplement 1, pp. 3522-3527, 2007.

[27] M.-T. Gao and Y.-Y. Wang, "Study and application on the technology of using the blasting to break roof to control rock burst," Journal of China Coal Society, vol. 36, supplement 2, pp. 326-331, 2011.

[28] Z.-Q. Xiong and H.-J. He, "Numerical simulation of rock burst stress and its control by stress-relief," Journal of Mining \& Safety Engineering, vol. 23, no. 4, pp. 489-493, 2006. 


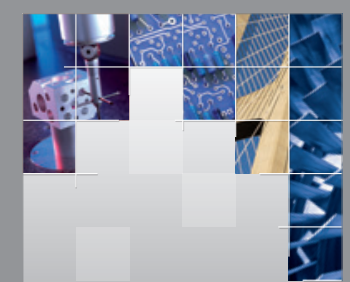

\section{Enfincering}
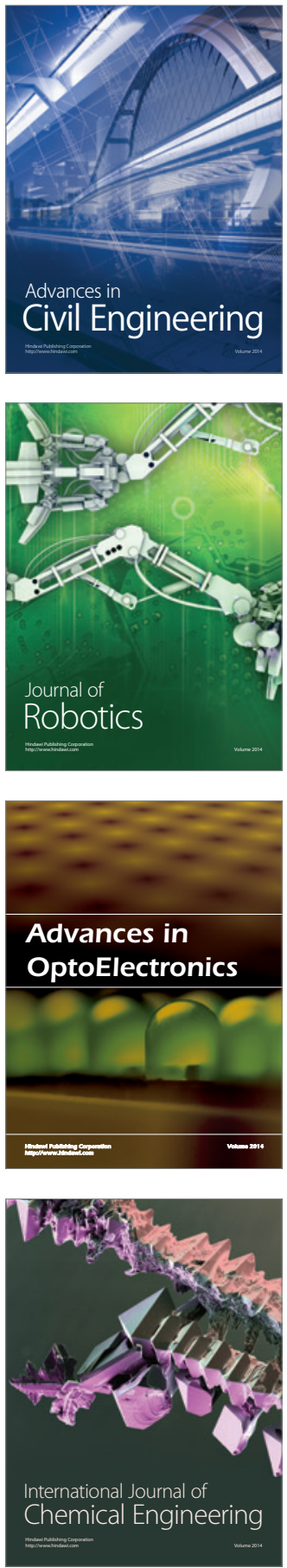

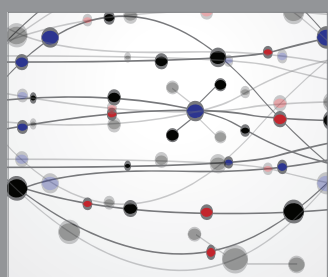

The Scientific World Journal

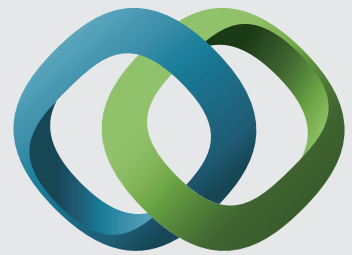

\section{Hindawi}

Submit your manuscripts at

http://www.hindawi.com
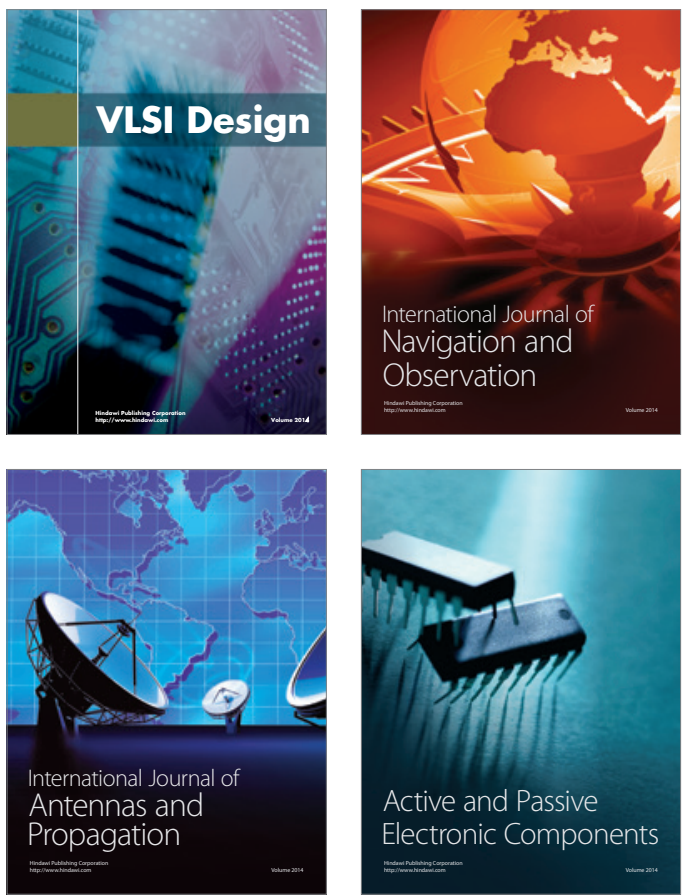
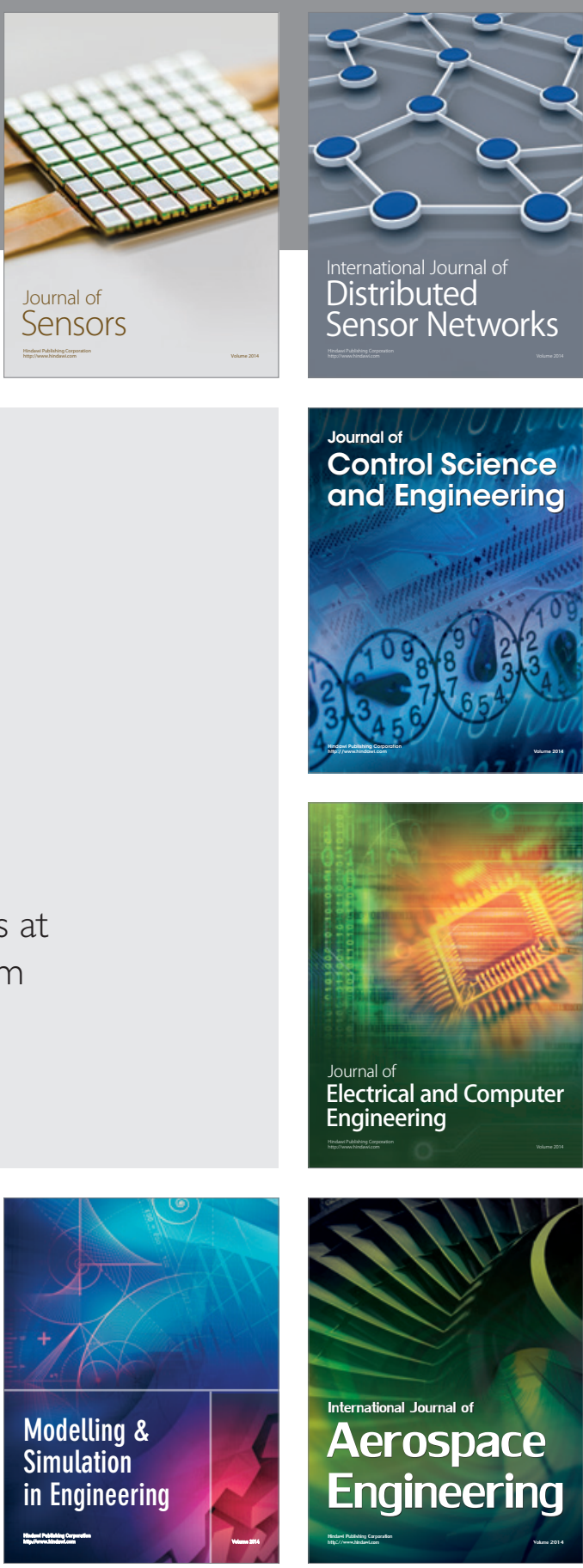

International Journal of

Distributed

Sensor Networks

Journal of

Control Science

and Engineering
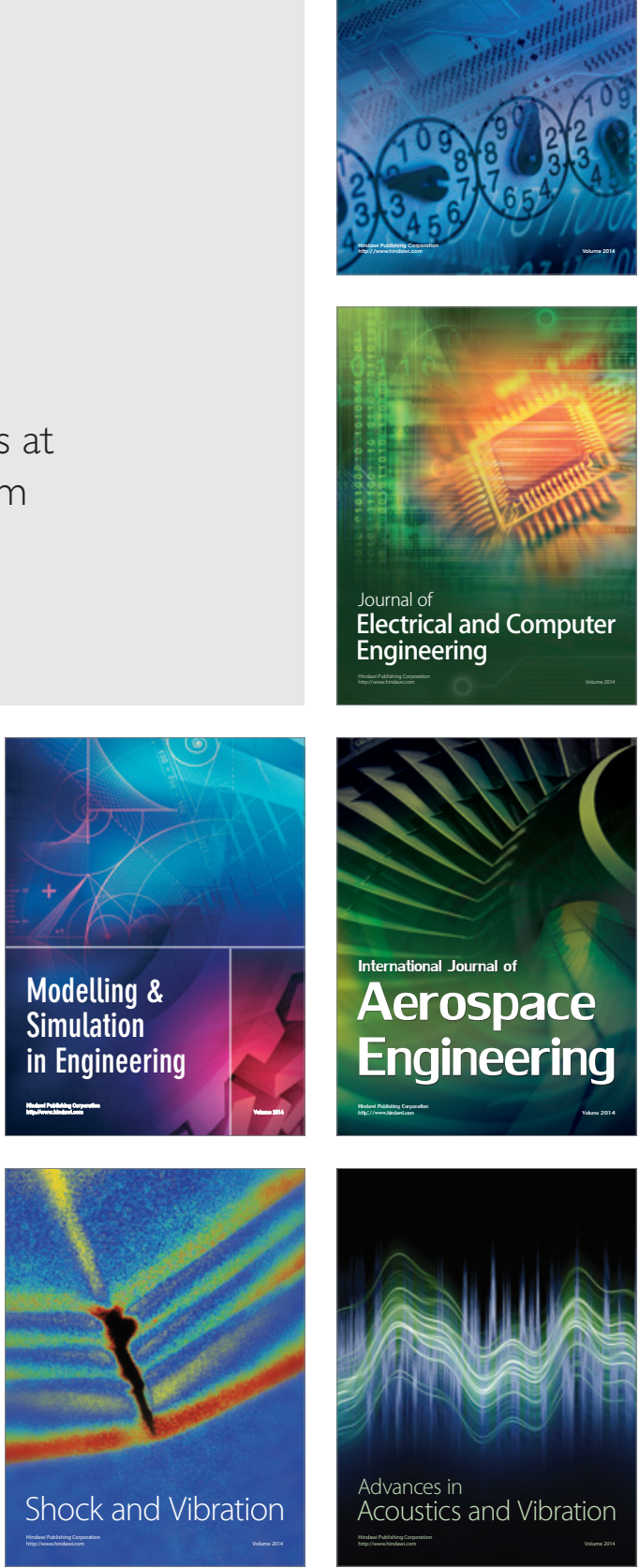